Pre-Publication Copy

Reference: Thomas, G.M. and Banks, T. (2013). 'We aren’t racing a fair race': Rawls, Sen, and the Paralympic Games. Sociological Research Online 18(3), 14

\title{
'We Aren't Racing a Fair Race': Rawls, Sen, and the Paralympic Games
}

\section{Gareth M. Thomas and Tim Banks}

\begin{abstract}
Following the final of the 200 metres in the London Paralympics 2012, athlete Oscar Pistorius criticised the prosthetic leg ('blade') length of Alan Oliveira, a fellow athlete and eventual winner of the race, and accused the International Paralympic Committee of failing to implement fair stipulations. Pistorius' contention directs attention toward an issue largely ignored in the sociological spectrum: the concept of fairness in the sporting arena. Drawing on the accounts of John Rawls (1971) and Amartya Sen (2009), specifically in terms of considering justice as fairness, we deconstruct the principle of fairness in the Paralympics which is currently framed within scientific discourse determining the validity of both athletes and performance-enhancing technologies. By identifying how the Paralympics adopts a Rawlsian understanding of fairness, we explore the work of Sen to highlight its complexity in this context and the need to retreat from taken-for-granted assumptions informing current knowledge.
\end{abstract}

Keywords: Fairness, Paralympics, Rawls, Sen, Sport

'We aren't racing a fair race' (Oscar Pistorius, London Paralympics)

\section{Introduction: Pistorius vs. Oliveira}

Despite the commercial success of the London Paralympics, the event was not devoid of controversy. During the final of the 200 metres, Oscar Pistorius lost to Alan Oliveira, a fellow athlete similarly running on prosthetic blades. Pistorius raised his concerns about an unfair advantage by criticising the length of Oliveira's and other athletes' blades which allegedly allowed them to 'run ridiculous times'. He censured the regulations specified by the International Paralympic Committee (IPC) before claiming that his previous objections on the 
same matter were 'falling on deaf ears'. Oliveira reacted by highlighting how he had undertaken the correct IPC procedures for ensuring that his blades were legal. The IPC responded to Pistorius' protests by supporting Oliveira's contentions, namely, that blade size is determined by a formula based on the attributes of the athlete and that Oliveira had fairly adhered to such regulations.

This incident serves to highlight how fairness, as a fundamental principle in the organisation of all sports, has been framed - and we suggest inhibited - in the Paralympic realm by definitions pertaining to scientific measurements of athlete participation (i.e. classification systems) and technological implementations. This (mistakenly) suggests that fairness is a universal end determined by scientifically-oriented instruments. Whilst the ideas established here can translate to other sporting contexts, we suggest that the fragile and complex relationship between the Paralympics, athletes, and technology establishes it as a fascinating case worthy of independent attention. Additionally, we suggest (with reference to the work of Rawls and Sen) that it represents a primary example of how fairness within sport can be comprehended in narrow yet overarching terms which fail to account for the intricacy and disorderliness of our world.

\section{The Paralympics: A Rawlsian Model}

In A Theory of Justice (1971: 3), Rawls presents his main idea of justice as fairness, a 'theory of justice that generalizes and carries to a higher level of abstraction the traditional conception of the social contract'. He regards justice as the first virtue of social institutions, together with acknowledging how a universal sense of justice as fairness is achieved among rational beings 'in an initial situation that is fair' (1971: 12). His two principles for establishing justice as fairness are the liberty principle, in which individuals have an equal right to 'basic liberty compatible with a similar liberty for others', and the equality principle, in which social and economic inequalities are arranged so they benefit everybody and are 'attached to positions and offices open to all' (1971: 60). Under a 'veil of ignorance', members of a society are encouraged to base justice on these principles and establish a set of agreed rules where social preconditions are veiled, thus producing a fair and egalitarian system (1971: 19). 
We suggest that the Paralympics (and aspects of other sports) adopts a parochial, Rawlsinspired understanding of justice as fairness confined within scientifically-oriented disputes around athletes' participation and the legality of technological manipulations (Marcellini et al. 2012). Athletes, for instance, are evaluated by technical officials and placed into classes based on their sporting ability which is subsequently viewed as providing a fair contest. In the The London 2012 Guide to the Paralympic Games (LOCOG 2012: 43-4), fairness is primarily grounded in explanations of the classification system which helps to 'group athletes with similar capabilities together in fair and equitable competition'. In disability swimming, for instance, the statistical difference in race performance between adjacent classes is used to 'judge validity (fairness)' (Daly and Vanlandewijck 1999: 271). This principle finds its home in many other Paralympic sports, particularly those involving technological innovations. The Paralympics guide explains how certain stipulations, including wearing masks in goal-ball 'to ensure everyone competes equally' (LOCOG 2012: 49) or wearing blindfolds in soccer 'to ensure fairness since there are many levels of visual impairment' (2012: 32), are established in the name of 'equality' and 'fairness', terms employed interchangeably throughout the guide.

Technological developments are embraced as inclusive artefacts ensuring that athletes are afforded the opportunity to perform at a competitive level and fulfil their bodily potential in a fair manner. Indeed, Pistorius' complaint after the final was precisely grounded in the legitimacy of Oliveira's blades. Fairness, thus, is enclosed within scientific validation; if Oliveira's blade fell within the limits imposed by the IPC, then Oliveira ran a fair race. Whilst this complicated relationship between technology, fairness, and the legality of scientific innovations has been recognised in both academia (Burkett et al. 2011) and the media, particularly with reference to Pistorius, we want to highlight how the scientific discourse around fairness, with regards to athletes' physical characteristics and performanceenhancing technologies, pertains to a contracted contemplation. We identify how this approach reflects a Rawlsian perspective of justice as fairness which, by attempting to promote a universal definition, discounts practical realities and the plurality of the concept.

\section{Deconstructing Fairness: Sen and the Paralympics}

Given that current understandings of fairness rests on predictive assumptions about inclusivity, thereby ignoring what the term truly encapsulates, we turn to the work of Sen 
(2009) to deconstruct the concept more critically. Whilst Sen agrees with Rawls' understanding of justice as fairness, he argues instead for a capabilities approach to justice over Rawls' functionalism. In particular, Sen criticises Rawls' binary model which suggests that fairness is either achieved or not achieved rather than existing to a degree, together with questioning his supposition that justice is only ever achievable when members of a given society establish a consensus. According to Sen, this romantic perspective suggests a global unity which does not reflect modern, multifarious conditions. The concept of justice (as fairness) is much more convoluted, plural, and local given that the triumph of 'perfectly just social arrangements is incurably problematic' (Sen 2009: 11).

Consider, for instance, the notion of sporting fairness in economic terms and the realistic access by some countries to materials enjoyed by more prosperous competitors. In the London Paralympics, Cambodia sent just one athlete to the Games yet the country has the highest concentration of amputees in the world (Usborne 2012). Even when athletes from countries with a low GDP per capita like Cambodia are able to compete, we can assume the monetary investment in both sport and technological innovation will be unable to replicate the standard achieved by superpowers like China and the US (Den Butter and Van Der Tak 1995). Taking Paralympic equestrianism as another example, athletes are divided into four grades and visually impaired riders are permitted to use 'callers' to help orientate themselves around the arena (LOCOG 2012). These rules are imposed in the name of fairness by levelling the playing field. Fairness in this context, again, is not extended to perceiving whether athletes have sufficient access to technologies such as horses, stables, or saddles.

This corresponds to Sen's (1992) capabilities approach, a flexible framework purporting that freedom to achieve fairness (or other social phenomena) is a product of what individuals are realistically able to do, that is, their capability to pursue what they perceive to be valuable. Capabilities are an individual's real opportunities to achieve 'functionings' ('beings and doings'), namely, a variety of states in individuals and worldly activities they can take on (Sen 1992). So whilst participating in the Paralympics can be identified as the functioning (specifically the 'doing'), the realistic opportunity to attain this goal can be defined as the capability. We suggest that reflecting on equity of access (as a capability) in the Paralympics highlights how technology is, at once, a great equaliser and divider, simultaneously including and excluding. Whilst talent undoubtedly has an instrumental role to play in success, a 
competition in which variation depends on the artificial limbs, wheelchairs, and other aids available to diverse individuals challenges what is meant when we describe a competition as fair, that is, whether individuals are credibly capable of pursuing desired ends.

By further considering Sen's capabilities approach, we also identify how bodily impairment and its treatment within wider socio-political contexts may challenge assumptions of fairness. According to the likes of Munyi (2012) and Gaad (2004), for instance, individuals with impairments in some areas of Nigeria can be viewed as evil and hopeless, with specific cultural beliefs potentially attributing these qualities to witchcraft, juju, or other supernatural forces. Whilst this represents an extreme example, it reveals the significance of reflecting on social context when contemplating the politics of impairment and, for our intentions here, the concept of fairness in Paralympic sport; different impairments, indeed, have different implications in different locales. Opportunities for sporting engagements may depend on social positioning, prejudices, and wider perceptions of impairment based on diverse cultural beliefs and/or a disablist climate. What is more, capabilities will depend on other important factors such as wealth, infrastructure, and the public profile of - and financial investment in certain sports. Here, we identify how the complexity of fairness requires unpacking beyond scientific accounts with reference to diverse deliberations such as those highlighted above.

To further capture the complexity of fairness, we draw attention to biological (dis)advantage. Savulescu et al. (2004) suggest that discrepancies in competitors' biological and genetic make-up can create vast advantages and disadvantages in athletes. They cite the case of skier Eero Maentyranta, winner of three gold medals in 1964, who had a genetic mutation resulting in the production of $40-50 \%$ more red blood cells than the average individual, a significant advantage in endurance events. Whilst this example is drawn from the able-bodied Olympics, it demonstrates how certain biological conditions create an uneven playing field and, thus, unfair sporting conditions.

Biological disadvantage has sometimes been resolved by athletes using performanceenhancing drugs, another area which holds a close relationship with framings of fairness as beyond scientific-based explanations. Whilst doping, for instance, is banned owing to providing too much of an athletic advantage in scientific terms, much of its disparagement as one of the ultimate sporting sins - corresponds to its essentially moral character; doping 
falsifies the competition and fails to obey the sporting ideal of fairness and ensuring a level playing field. Another example is boosting, a practice in which athletes with spinal injuries purposely harm themselves (e.g. using tight leg straps) to increase blood pressure and subsequently enhance performance. Both boosting and doping are acknowledged by the IPC as illegal performance-enhancing technologies which do not uphold the 'spirit of sport' (World Anti-Doping Agency 2009).

Interestingly, other (more effective) technologies enhancing performance are regarded as fair and are not subjected to similar derision. Hypoxic air machines, for example, boost the production of red blood cells by increasing the oxygen-carrying capacity of the blood, arguably a form of technodoping. However, the World Anti-Doping Agency ruled that such machines, despite enhancing performance and violating the spirit of sport, are fair and would not be banned as a method of improving athletic performance (Karp 2011). Doping, in contrast, is strictly banned, despite ensuring a similar outcome to the hypoxic air machines, since it is viewed as unfair, harmful, and disturbing the 'spirit of sport'. It has been proposed that some widely accepted technologies actually create a greater advantage than the best performance-enhancing drugs, with Savulescu et al. (2004: 666-8) contending that legalising drug use in sport could ensure 'fairer' competition and 'levelling the playing field' by remedying biological (and other) inequalities. This all highlights how fairness, far from being confined to scientifically-oriented disputes about athlete classification and the use of certain technologies, is bound up in moralistic sentiments which determine whether behaviour or technologies are acknowledged as just and fair. This also corresponds to an implicit and informal idea of sportsmanship or 'fair play' as an ethical value (Dunning and Sheard 1979). Here, we have attempted to appropriately capture individual differences (i.e. human diversity), an important dimension for Sen since it may lead us to ask what means are significant (and available) for the fostering and nurturing of a capability.

\section{Discussion}

Whilst space precludes a heavy engagement with all aspects of social/cultural, economic and biological (dis)advantage, together with sporting morals and other reflections on what else may enhance wider discussions of fairness ${ }^{1}$, our primary purpose is to highlight the precarious nature of fairness in Paralympic sport and how it is, in turn, far more complicated than the scientific discourse of physical characteristics and technical engagements organising 
current disputes. Fairness, in adopting Sen's stance, is a wholly pluralistic idea which requires interpersonal comparisons of distinct contexts rather than assuming a (Rawlsian) universalising principle. His capabilities approach directs attention toward the importance of considering an individual's 'social realisations', that is, 'the power to do something' (Sen 2009: 19). This, we contend, becomes central to the analysis of fairness in the Paralympics.

Sen strives for an approach which accounts for competing reasons for fairness; his story of three children and their claims to taking ownership of a flute, whereby they all provide (fair) reasoning for their claims, clearly illuminates this plurality (2009: 12-5). Sen's flute story corresponds to his acknowledgement of 'conversion factors' which influence how an individual is able to convert resources into functionings (Sen 1992); in the Paralympics, whilst biological unfairness can correspond to personal conversion factors (e.g. sex, genetic make-up), social/cultural and economic unfairness can characterise social conversion factors (e.g. public policies, social norms, power relations). Sen uses his theory of capability to acknowledge how the opportunities made feasible by internal and external conversion factors, thus, reveal the plurality of fairness as a concept. To realise this comprehension of plurality, Sen suggests taking the position of the 'impartial spectator' (Smith 1759; cited in Sen 2009: 44), he or she who takes account of 'a variety of viewpoints to garner diverse opinions rather than limiting oneself to close encounters with those within a familiar social and cultural territory'. By taking account of difference, Sen claims that we can gather a more holistic view of justice as fairness, account for human diversity, and form an understanding not feigning precision or allusions to a universal truth. In sum, we contend that Sen's functionings and capabilities framework, of distinguishing between the realised and the effectively possible, can highlight how fairness may be conceptualised in the Paralympic context.

Debates about fairness, in the guise of justice and equality, remain intrinsic to the organisation of Paralympic sport, which commonly corresponds to the use of technological manipulation to ensure participation. The world of scientific prosthetics and technological innovation is progressing at a rapid pace, posing difficult questions for the IPC and athletes alike. Should the Paralympics embrace the augmentation of technological manipulation based purely on its availability? What impact will this have on our understandings of fairness and for offering a fair competition? Such developments should undoubtedly be framed by wider 
discussions surrounding how we understand fairness within sport. We may even ponder, in turn, whether absolute fairness is an idealistic construct forever beyond our clutches.

\section{Footnotes}

1. How the Paralympics has moved from a therapeutic practice to a commercial sporting event, for instance, could influence discrepancies and debates around fairness. Whilst we appreciate this point from an anonymous reviewer, we do not have the space to explore this further.

\section{References}

BURKETT, B., McNamee, M. and Potthast, W. (2011) Shifting boundaries in sports technology and disability: equal rights or unfair advantage in the case of Oscar Pistorius? Disability \& Society 26(5), pp. 643-654.

DALY, D.J. and Vanlandewijck, Y. (1999) Some criteria for evaluating the "fairness" of swimming classification. Adapted Physical Activity Quarterly 16(3), pp. 271-289.

DEN BUTTER, F.A.G. and Van Der Tak, C.M. (1995) Olympic medals as an indicator of social welfare. Social Indicators Research 35(1), pp. 27-37.

DUNNING, E. and Sheard, K. (1979) Barbarians, Gentlemen and Players: A Sociological Study of the Development of Rugby Football. Oxford: Martin Robertson.

GAAD, E. (2004) Cross-cultural perspectives on the effect of cultural attitudes towards inclusion for children with intellectual disabilities. International Journal of Inclusive Education 8(3), pp. 311-328.

KARP, H. (2011) Novak Djokovic's secret: sitting in a pressurised egg [Online] Available at: <http://online.wsj.com/article/SB10001424053111904787404576532854267519860.html> (Accessed: 24 May 2013).

LOCOG. (2012) The London 2012 guide to the Paralympic Games [Online]. Available at: $<$ http://www.london2012.com/mm\%5CDocument\%5CPublications\%5CJoinin\%5C01\%5C24 
\%5C08\%5C10\%5Clondon-2012-guide-to-the-paralympic-games.pdf> (Accessed: 24 May 2013).

MARCELliNI, A., Ferez, S., Issanchou, D., De Leseleuc, E. and McNamee, M. (2012) Challenging human and sporting boundaries: the case of Oscar Pistorius. Performance Enhancement and Health 1(1), pp. 3-9.

MUNYI, C.W. (2012) 'Past and present perceptions towards disability: a historical perspective', Disability Studies Quarterly: The First Journal in the Field of Disability Studies, Vol. 32, Issue. 2, <http://dsq-sds.org/article/view/3197/3068>.

RAWLS, J. (1971) A Theory of Justice. Oxford: Clarendon Press.

SAVULESCU, J., Foddy, B. and Clayton, M. (2004) Why we should allow performance enhancing drugs in sport. British Medical Journal 38(6), pp. 666-670.

SEN, A. (1992) Inequality Re-examined. Oxford: Clarendon Press.

SEN, A. (2009) The Idea of Justice. Cambridge, MA: Belknap Press/Harvard University Press.

USBORNE, S. (2012) The race is on in the hi-tech Paralympics [Online]. Available at: $<$ http://www.independent.co.uk/sport/olympics/paralympics/the-race-is-on-in-the-hitechparalympics-8092782.html> [Accessed: 24 May 2013].

WORLD ANTI-DOPING AGENCY. (2009) World Anti-Doping Code. Canada: World AntiDoping Agency. 